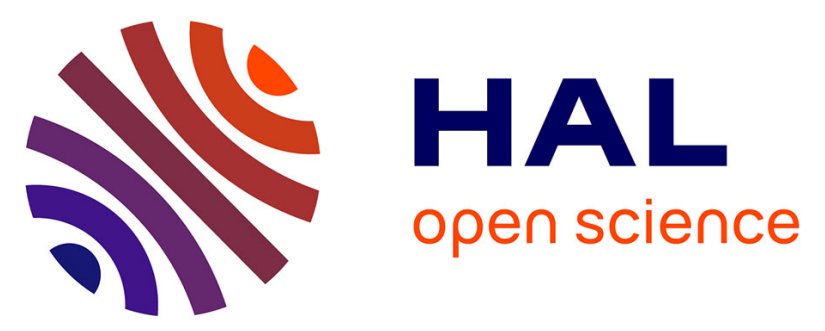

\title{
Mechanical-tuning of the cooperativity of SC particles via the matrix crystallization and related size effects
}

\author{
Jerome Laisney, Denis Morineau, Cristian Enachescu, Radu Tanasa, Eric
}

Riviere, Régis Guillot,, M.-L. Boillot

\section{- To cite this version:}

Jerome Laisney, Denis Morineau, Cristian Enachescu, Radu Tanasa, Eric Riviere, et al.. Mechanicaltuning of the cooperativity of SC particles via the matrix crystallization and related size effects. Journal of Materials Chemistry C, 2020, 8 (21), pp.7067-7078. 10.1039/d0tc00067a . hal-03268406

\section{HAL Id: hal-03268406 https://hal.science/hal-03268406}

Submitted on 24 Jun 2021

HAL is a multi-disciplinary open access archive for the deposit and dissemination of scientific research documents, whether they are published or not. The documents may come from teaching and research institutions in France or abroad, or from public or private research centers.
L'archive ouverte pluridisciplinaire HAL, est destinée au dépôt et à la diffusion de documents scientifiques de niveau recherche, publiés ou non, émanant des établissements d'enseignement et de recherche français ou étrangers, des laboratoires publics ou privés. 
Mechanical-tuning of the cooperativity of SC particles via the matrix crystallization and related size effects

J. Laisney, D. Morineau, C. Enachescu, R. Tanasa, E. Rivière, R. Guillot, M.-L. Boillot Journal of Materials Chemistry C, 2020, Royal Society of Chemistry, DOI: 10.1039/d0tc00067a. 


\title{
Mechanical-tuning of the cooperativity of SC particles via the matrix crystallization and related size effects
}

\author{
Jérôme Laisney, ${ }^{a} \dagger$ Denis Morineau, ${ }^{b^{*}}$ Cristian Enachescu, ${ }^{{ }^{*}}$ Radu Tanasa, ${ }^{c}$ Eric Rivière, ${ }^{a}$ \\ Régis Guillot, ${ }^{a}$ Marie-Laure Boillot ${ }^{a^{*}}$ \\ (a) Université Paris-Saclay, CNRS, Institut de Chimie Moléculaire et des Matériaux d'Orsay, 91405, Orsay, \\ France \\ (b) University of Rennes 1, Institut de Physique de Rennes, UMR UR1-CNRS 6251, 35000 Rennes, France \\ (c) Faculty of Physics, Alexandru Ioan Cuza University, 700506 Iasi, Romania. \\ † Present address: Dept of Plant and Soil Sciences, University of Kentucki, Lexington, Kentucky, 40546, \\ USA. \\ * Corresponding author
}

\begin{abstract}
We investigate the composites formed by a volume-changing material with a first-order spin transition [Fe ${ }^{\mathrm{III}}\left(3-\mathrm{OMeSalEen}_{2}\right] \mathrm{PF}_{6}$, when incorporated into a matrix of 1-butanol with a combination of calorimetric and magnetic measurements. DSC evidences the multiple phase transitions of the composite and the experimental conditions to select for promoting a possibly double phase transition of 1-butanol (crystallization) on both sides of the spin transition. Cycling the compound in the liquid matrix preserves the spin-transition properties of the reference with a $1 \mathrm{~K}$ wide hysteresis. In contrast, the crystallization around low-spin (high-spin) particles leads to changes in the heating (cooling) branch resulting in a non-persistent (persistent) hysteresis and a positive (negative) temperature shift, as a consequence of the environmental pressure experienced by the particles. The relaxed hysteretic regime that requires the crystallization of butanol around the high-spin particles of higher volume was studied by first-order reversal curves (FORCs) technique. The particular shape of FORCs shows a cooperative mechanism and the absence of the reversible component that was previously assigned to particles-matrix elastic interactions. The first-order spin transition of a single-crystal was characterized with X-ray diffraction measurements in presence of a thin layer of 1-butanol. The temperature dependence of the volume and unit-cell parameters reproduces the changes characterizing the matrix solidification around an ensemble of low-spin (butanol coating) or high-spin (paratone coating) particles. It is also shown that the increase of cooperativity resulting from the mechanical interactions taking place in the particle-matrix system can partly counterbalance the loss of cooperativity observed when reducing the size of the spin-transition materials.
\end{abstract}

\section{Introduction}

A central question in the generation of composites is how the properties of a specific object combine with those of other constituents of a whole. 1 In this context, recent studies of nanomaterials have shown that the introduction of coating and interface (with component, matrix or substrate) influences the behavior and conversely this interaction can be exploited to trigger new functionalities. However the current development is somewhat limited by the fact that the structure-property relationship that accounts for the multiscale behavior of these nanocomposites is not yet well understood. This paper focuses on spin-crossover (SC) molecular materials $\stackrel{2-4}{-}$ whose processability at nanoscale in addition to their cooperativity and bistability make them attractive for further technological developments (information storage, sensing, 
actuating). .5 Within the solid, the molecules reversibly switch between a low spin (LS) and a high spin (HS) state in response to external stimuli such as temperature, pressure or light irradiation. $\underline{2-4}$ The associated change of molecular volume produces elastic interactions mediating cooperative transformations. For high-enough cooperative interactions, the spin-state switching takes place via a first-order SC transition with a hysteresis loop. As the SC molecules are active on their environment and sensitive to it, a major issue consists in their downsizing and insertion into devices without any alteration of their unique cooperative properties. 6 In the past decade, SC materials have been processed in form of nanoparticles, especially by using wet approaches. With scarce exceptions, $\rightarrow \underline{7}$ the nanoparticles coated with polymers or surfactants exhibit incomplete SC, which are shifted towards lower temperatures and less cooperative than the bulk ones, while the hysteresis have smaller widths or even vanish. .9 These features mainly result from the prevalence of the particles surface / matrix interface as established with models based on mechano-elastic, $\underline{10}$ thermodynamic $\underline{11}$ and electro-elastic $\underline{12}$ approaches. Moreover the environment influences the cooperativity and bistability in a non-trivial manner for a broad range of particle size. $.13-20$ One striking result was the presence of a hysteresis during the SC of anisotropic $\left(10 \times 10 \times 5 \mathrm{~nm}^{3}\right)$ nanoparticles, $\underline{17}$ when introducing a thin enough silica external layer. In the case of particles of much lower surface/volume ratio, evidences of an effect were also perceived. The simple dispersion of microcrystals in liquid, glassy or semicrystalline media leads to continuous SC or hysteretic transformation. 21 Several studies showed that the latter was of non-cooperative nature and derived from the interference between the glass-transition of the matrix $\left(\mathrm{T}_{\mathrm{g}}\right.$ ) and the spin transition ( $\mathrm{T}_{\mathrm{g}}$ close to $\mathrm{T}_{1 / 2}$, the transition temperature). The opening of a hysteresis was attributed to the switching on and cutting off of matrix-particles elastic interactions, which depend on the volume of SC particle and the state of the matrix. These hypotheses were first supported by a mechano-elastic analysis, $\underline{22}$ then by magnetic investigations using the first-order reversal curve technique and their combination with calorimetric measurements. $\underline{23}$ These observations were compared with other examples of bulk materials. $\underline{\underline{24}}$ Nevertheless, apart the role played by the proximity between the spin transition and the glass transition, very little is known on the relationship between the composite state and the physicochemical properties of the matrix.

In order to better understand the mechanism leading to the bistability and to unravel the matrix and size reduction effect, we investigate here the SC particles embedded in an environment with adjustable properties in the temperature range of the first-order spin transition. We selected a first-order spin-transition material, $\mathrm{Fe}^{\mathrm{III}}$ (3-OMeSalEen) ${ }_{2} \mathrm{PF}_{6}$ with $3 \mathrm{~K}$ wide hysteresis centered at $\mathrm{T}_{1 / 2}=163.5 \mathrm{~K} . \underline{25}, \underline{26}$ The Fe ${ }^{\text {III }}$ compound was prepared in form of micro- and nanocrystals (8(4)x0.7(0.3)x0.15(0.07) $\mu \mathrm{m}^{3}$ and 460(140)x200(50)x35(10) $\mathrm{nm}^{3}$, respectively, see Fig. S1 in ESI) 27 then post-embedded in a molecular matrix of 1-butanol. To properly characterize the phase transitions of the particles - matrix system, we use modulated differential scanning calorimetry (m-DSC). $\underline{28}$ This technique has been applied, mainly in the non-modulated form, to cooperative first-order spin transition materials $29-31$ including the $\mathrm{Fe}$ III compound under study. $\underline{32}$ The present work was conducted with combined calorimetric and magnetic measurements, and as structural features may be impacted as well, with single-crystal X-ray diffraction measurements. The magnetic analysis of the hysteretic behavior lies on the application of the First-Order Reversal Curves (FORC) technique that allows to unambiguously characterize the cooperativity $\underline{33,34}$ and resolve components due to reversibility or kinetic effects. $\underline{35}$

\section{Results and discussion}


For the sake of simplicity, we limit the description in the different sections below to the main observations while the whole data set is included in the supplementary information part.

\section{A. Phase Transitions of Pure and Composite Systems: Thermodynamical Study}

The differential scanning calorimetry measurements were carried out with bulk and microparticles samples. The experimental conditions were fixed with respect to the temperature range (comprised within the range $100-200 \mathrm{~K}$ ) and the scanning rate ( 1 and $10 \mathrm{Kmin}^{-1}$ ) required for detecting the phase transition of 1-butanol and of the SC sample (bulk and microcrystals). A classical DSC and modulated mode (m-mode) were used (see SI for experimental details). In mDSC mode, the acquisition of the in-phase and out-of-phase contributions to the total modulated heat flow, allowed us disentangling between the contributions of both the sample heat capacity and enthalpy of reversible phase transformations (e.g. heat capacity jump at $\mathrm{T}_{\mathrm{g}}$, melting and spin-transitions) and the non-reversing contributions (e.g. heat capacity relaxation around $\mathrm{T}_{\mathrm{g}}$ and crystallization of the supercooled liquid). In m-DSC mode, the acquisition of the in-phase and out-of-phase contributions to the total modulated heat flow, allowed us disentangling between the contributions of both the sample heat capacity and enthalpy of reversible phase transformations (e.g. heat capacity jump at $\mathrm{T}_{\mathrm{g}}$, melting and spin-transitions) and the nonreversing contributions (e.g. heat capacity relaxation around $\mathrm{T}_{\mathrm{g}}$ and crystallization of the supercooled liquid).

Then, carefully designed thermal cycles were applied in order to drive the matrix in different well-defined thermodynamic states from which the thermal evolution of the spin-crossover particles was extracted. In Tab. 1 are collected the thermodynamical parameters extracted from these experiments.

Pure sample of FeIII(3-OMeSalEen) $\left.{ }_{2}\right] \mathrm{PF}_{6}$ and 1-butanol. First we checked that the thermal cycling of the bulk material (Fig. S2) reproduced the characteristics of the first-order spin transition $^{27}\left(\mathrm{~T}_{1 / 2}=162.3 \mathrm{~K}, \Delta \mathrm{H}=4.94-5.94 \mathrm{kJmol}^{-1}\right)$. In Fig. S3, we present the thermogram of 1butanol acquired in the range $100-200 \mathrm{~K}\left(10 \mathrm{Kmin}^{-1}\right)$. On cooling, it is noteworthy that the supercooled liquid does not crystallize, but presents a glass transition at $\mathrm{T}_{\mathrm{g}}=118.1 \mathrm{~K}$.

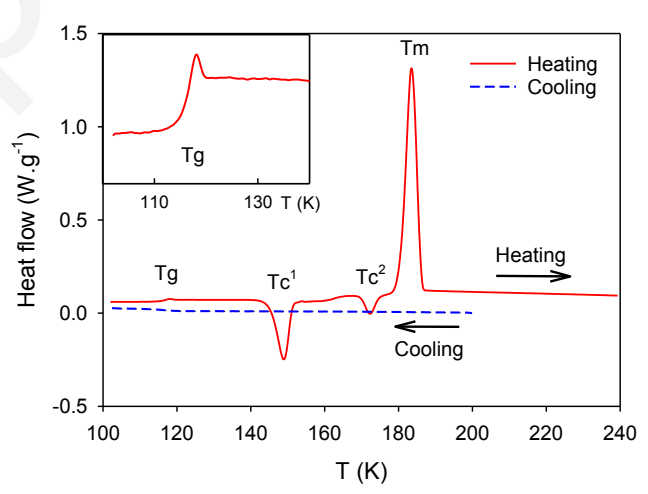

Figure 1. Thermogram of 1-butanol $\left(1 \mathrm{Kmin}^{-1}\right)$ recorded after the thermal equilibration $(200 \mathrm{~K}$, $5 \mathrm{~min}$ ), along with a full cycle between 200 and $100 \mathrm{~K}$ on cooling (---) and on heating (-). The DSC measurement characterizes the glass transition at $\mathrm{T}_{\mathrm{g}}=116.0 \mathrm{~K}$; a secondary crystallization at $\mathrm{T}_{\mathrm{c}}{ }^{1}=148.8 \mathrm{~K}$; the crystallization in the triclinic phase at $\mathrm{T}_{\mathrm{c}}{ }^{2}=172.2 \mathrm{~K}$ which vanishes in the reversing heat flow (inset in Fig. S6), then the melting at $\mathrm{T}_{\text {melt }}=183.4 \mathrm{~K}$. Inset: heating branch magnified in the region of the glass transition. 
Upon heating, the glass converts into a supercooled liquid that crystallizes (exothermic peak above $160 \mathrm{~K}$ ), then melts at $\mathrm{T}_{\mathrm{m}}=183.7 \mathrm{~K}$ (endothermic peak). Fig. S4 shows that applying this cooling down to $100 \mathrm{~K}$ with the subsequent heating scan interrupted at $180 \mathrm{~K}$, allows to generate a fully crystallized form of 1-butanol.

Table 1. Thermodynamical parameters of phase transitions of $\left.\mathrm{BuOH}, \mathrm{Fe}(3-\mathrm{OMeSalEen})_{2}\right] \mathrm{PF}_{6}$ (free or embedded particles) extracted from DSC thermograms collected at $1 \mathrm{Kmin}^{-1}$.

\begin{tabular}{|c|c|c|c|c|c|c|c|}
\hline \multicolumn{2}{|c|}{ Cooling/heating cycle } & \multicolumn{4}{|c|}{ Temperature (K) } & \multicolumn{2}{|c|}{ Enthalpy $\left(\mathrm{kJmol}^{-1}\right)$} \\
\hline [T range] & Label (n) & $\mathrm{T}_{\max } \downarrow$ & $\mathrm{T}_{\max } \uparrow$ & $\mathrm{T}_{1 / 2}$ & $\Delta \mathrm{T}$ & $\Delta \mathrm{H} \downarrow$ & $\Delta \mathrm{H} \uparrow$ \\
\hline & \multicolumn{7}{|l|}{$\mathrm{BuOH}$} \\
\hline & & - & $\begin{array}{l}148.8\left(\mathrm{~T}_{\mathrm{c}}{ }^{1}\right) \\
172.2\left(\mathrm{~T}_{\mathrm{c}}{ }^{2}\right)\end{array}$ & - & - & & $\begin{array}{l}5.34 \\
4.63\end{array}$ \\
\hline & \multicolumn{7}{|c|}{ Free particles } \\
\hline \multirow[t]{2}{*}{$\begin{array}{l}{[200-100-} \\
180 \mathrm{~K}]\end{array}$} & & $\begin{array}{l}162.9 \\
(162)\end{array}$ & $\begin{array}{l}163.9 \\
(164)\end{array}$ & $\begin{array}{l}163.4 \\
(163)\end{array}$ & $\begin{array}{l}1.0 \\
(2)\end{array}$ & 4.52 & 4.59 \\
\hline & \multicolumn{7}{|c|}{ Particles embedded in $\mathrm{BuOH}$} \\
\hline $\begin{array}{l}{[200-150-} \\
180 \mathrm{~K}]\end{array}$ & $\mathbf{b} \downarrow \mathbf{b} \uparrow$ & $\begin{array}{l}162.1 \\
(162)\end{array}$ & $\begin{array}{l}164.25 \\
(163)\end{array}$ & $\begin{array}{l}163.1 \\
(162.5)\end{array}$ & $\begin{array}{l}2.15 \\
\text { (1) }\end{array}$ & 4.84 & 3.15 \\
\hline $\begin{array}{l}{[200-100-} \\
180 \mathrm{~K}]\end{array}$ & $\mathbf{b} \downarrow \mathbf{c} \uparrow(1)$ & $\begin{array}{l}162.0 \\
(162)\end{array}$ & $\begin{array}{l}168.0 \\
(168)\end{array}$ & $\begin{array}{l}165 \\
(165)\end{array}$ & $\begin{array}{l}6.0 \\
(6)\end{array}$ & 4.82 & 1.09Rev \\
\hline $\begin{array}{l}{[180-100-} \\
180 \mathrm{~K}]\end{array}$ & $\mathbf{c} \downarrow \mathbf{d} \uparrow(2)$ & $\begin{array}{l}156.3 \\
(154)\end{array}$ & $\begin{array}{l}164.0 \\
(162)\end{array}$ & $\begin{array}{l}160.2 \\
(158)\end{array}$ & $\begin{array}{l}7.7 \\
(8)\end{array}$ & 3.93 & 4.28 \\
\hline $\begin{array}{l}{[180-100-} \\
180 \mathrm{~K}]\end{array}$ & $\mathbf{d} \downarrow \mathbf{d} \uparrow(3)$ & $\begin{array}{l}157.5 \\
(155)\end{array}$ & $\begin{array}{l}164.0 \\
(162)\end{array}$ & $\begin{array}{l}160.8 \\
(158.5)\end{array}$ & $\begin{array}{l}6.5 \\
(7)\end{array}$ & 3.86 & 4.28 \\
\hline
\end{tabular}

1-butanol, $\mathrm{T}_{\mathrm{g}}=118.1 \mathrm{~K}, \mathrm{~T}_{\mathrm{m}}=183.7 \mathrm{~K}, \mathrm{~T}_{\mathrm{c}}{ }^{1}$ and $\mathrm{T}_{\mathrm{c}}{ }^{2}$ being the crystallization temperatures; $\mathrm{T}_{1 / 2}=(\mathrm{T} \downarrow+$ $\mathrm{T} \uparrow) / 2 ; \Delta \mathrm{T}=\mathrm{T} \downarrow-\mathrm{T} \uparrow$; initial sample thermalization at $200 \mathrm{~K}$, cycle label in Tab. $2, \mathrm{n}=$ order in successive cycles. In italic, data obtained from magnetic measurements (same sample, scanning rate and thermal cycle).

On the contrary (Fig. S5) when the cooling branch is limited to $150 \mathrm{~K}$, only a minor fraction of 1 butanol crystallizes above $170 \mathrm{~K}$ during heating (4\% according to the enthalpy). The phase behavior of 1-butanol also depends on the value of the scanning rate. Fig. 1 shows that the glassy form of 1-butanol is also obtained with a slower cooling rate $\left(1 \mathrm{~K} \mathrm{~min}^{-1}\right)$. However, a different behavior is observed upon heating, with an exothermic peak centered at $\mathrm{T}_{\mathrm{c}}{ }^{1}=148.8 \mathrm{~K}$ (full transition range $145-150 \mathrm{~K}$ ) preceding a less intense one centered at $\mathrm{T}_{\mathrm{c}}{ }^{2}=172.2 \mathrm{~K}$ (full transition range 169-175 K). In the literature, the first signal at $\mathrm{T}_{\mathrm{c}}{ }^{1}$ was ascribed to a frustrated crystallization, i.e. the formation of small nanocrystals trapped in an essentially amorphous 
metastable phase, named glacial phase. $\frac{36-38}{38}$ The second signal at $\mathrm{T}_{\mathrm{c}}{ }^{2}$ arises from the crystallization of the stable triclinic phase. These temperature and rate-dependent features are consistent with a higher probability of nucleation at low temperature but a faster growth kinetic at high temperature. The opportunity to maintain the medium in a well-defined liquid or solid state was exploited for analyzing the properties of the composite. Notably, we found that the liquid phase of 1-butanol was preserved in a range of temperature overlapping that of SC by a thermal cycling down to $150 \mathrm{~K}$. Conversely, a complete crystallization of the most stable triclinic phase was achieved using a preparative cycle combining a cooling down to either 100 or $130 \mathrm{~K}$ and heating up to $180 \mathrm{~K}$ (see Fig. $1\left(1 \mathrm{Kmin}^{-1}\right)$ and Fig. S4 $\left(10 \mathrm{Kmin}^{-1}\right)$ ).

In-BuOH Bulk Samples. Based on the phase behavior of 1-butanol in the region of the SC transitions, three different situations were anticipated (liquid, unrelaxed -metastable- crystal and relaxed crystal) and actually observed for the composite system. The corresponding conditions are illustrated in Table 2 for both the HS-to-LS (cooling, left panel) and LS-to-HS (heating, right panel) transitions, and compared with the free SC particles. The case $\mathbf{b}$ corresponds to the situation where the matrix remains liquid during the spin transition.
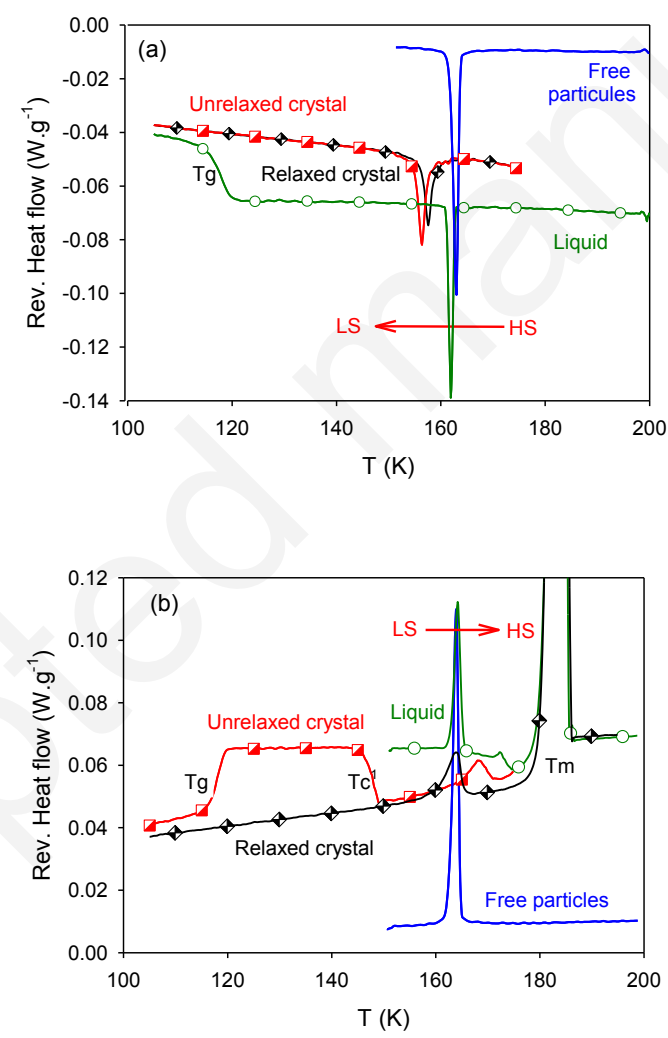

Figure 2. Reversal heat flow of the m-DSC thermogram $\left(1 \mathrm{Kmin}^{-1}\right)$ of bulk particles on cooling (a) and heating (b) in the region of the spin transition and for different conditions. Free particles (blue solid line), particles embedded in a liquid matrix (green open circle), unrelaxed crystal matrix (red semi-filled square) and relaxed crystal matrix (black hour-glass diamond).

The cooling and heating branches are labelled (b $\downarrow)$ and $(\mathbf{b} \uparrow)$, respectively. For a crystalline matrix, a difference was made for the situations when the SC transition occurs for the first time (unrelaxed crystal, case (c)) and the subsequent transitions (relaxed crystal, case (d)) induced by thermal cycling below $\mathrm{T}_{\mathrm{m}}$. The experiment was carried out with small crystals of $\mathrm{Fe}^{\mathrm{III}}(3-\mathrm{OMeSalEen})_{2} \mathrm{PF}_{6}$ embedded in liquid 1-butanol. In order to provide a first overview of 
the influence of the state of the matrix on the spin transitions of embedded particles, we superimposed in Figs. 2a-b the four m-DSC thermograms (1 $\left.\mathrm{Kmin}^{-1}\right)$ corresponding to the different situations listed in Tab. 2. For clarity, only the reversing heat flow is presented, so that the signature of the SC transitions is not obscured by the exothermic crystallization of 1-butanol. When appropriate, we also refer to the total heat flow of the corresponding m-DSC thermograms, which are shown in supplementary information. For a liquid matrix, which corresponds to the transitions named (b $\downarrow$ ) and (b $\uparrow$ ) in Table 2 (see Fig. 2 and Table 1), the SC features $\left(\mathrm{T}_{1 / 2}\right.$ liq $\left.=163.2 \mathrm{~K}\right)$ are closely related to those of free particles $\left(\mathrm{T}_{1 / 2}\right.$ free $\left.=163.4 \mathrm{~K}\right)$. The only noticeable difference is a decrease of the LS-to-HS peak intensity (reduction of $\Delta \mathrm{H} \uparrow$ value by $30 \%)$. However, it cannot be excluded that this smooth reduction of $\Delta \mathrm{H} \uparrow$ is due to the slow initiation of partial crystallization of the matrix, as suggested by the broad weakly exothermic peak in the total heat flow (Fig. S6) rather than the effect of the liquid matrix on the SC transition itself. It could proceed from internal heat exchanges between the matrix and the SC particles, which simultaneously undergo exothermic crystallization and an LS-to-HS endothermic transition, resulting in compensation effects that are not fully resolved within the measured heat flow despite thermal modulation.

Table 2. Schematics of the different types of SC transition observed for bulk particles embedded in 1-butanol matrix, depending on the state of the matrix and the thermal treatment (left: HS-LS transition on cooling, right: LS-HS transition on heating).

On cooling (HS-to-LS transition) On heating (LS-to-HS transition)
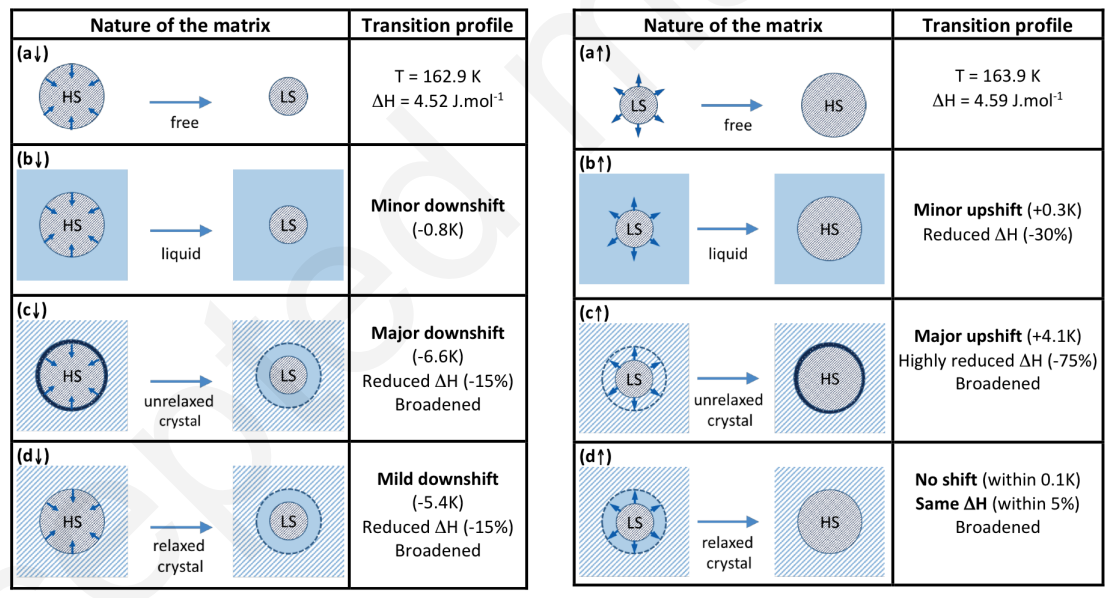

For a crystalline matrix, a difference between the first cooling (resp. heating) across the SC transition and the following thermal cycles is visible for both the HS-to-LS and the LS-to-HS transitions. Considering first the HS-to-LS transition shown in Fig. 2a, we observed a negative shift of the transition during the first cooling of the crystalline matrix (case (c $\downarrow$ ) in Tab. 2), with a reduction of about $-6.6 \mathrm{~K}$ of $\mathrm{T} \downarrow$ (max) with respect to free particles and a broadening of the transition. On further cycling the crystalline state of the composite (case (d $\downarrow$ ) in Tab. 2), the negative shift of HS-to-LS transitions slightly relaxed (c.a. $-5.4 \mathrm{~K}$ ), while the transition remained comparable in terms of broadening and enthalpy. Considering now the LS-to-HS transition shown in Fig. 2b, it presented first (case (c $\uparrow$ ) in Tab. 2) a positive shift of the transition with respect to the free particles or to the SC-liquid composite, with an increase of $\mathrm{T} \uparrow$ (max) of about $4 \mathrm{~K}$, and a broadening of the transition. In subsequent cycles, the LS-to-HS transition (case (d $\uparrow$ ) 
in Tab. 2) later stabilized to values of $\mathrm{T} \uparrow(\max )$ and $\Delta \mathrm{H} \uparrow$ that conform with those of free particles, albeit remaining broadened.

In the following, we develop two interesting outcomes from this m-DSC study, which first concern the possible mechanisms that link the properties of the matrix to the spin transitions of the embedded particles, and then, the resulting behavior of the composite system along different thermal paths. The remarkable changes in the hysteretic behavior of $\left.\mathrm{Fe}^{\mathrm{III}}(3-\mathrm{OMeSalEen})_{2}\right] \mathrm{PF}_{6}$ take place after two phase transitions of $\mathrm{BuOH}$ leading to changes in the environment characteristics of particles (crystallinity, density, volume, stiffness, texture, thermodynamical stability, ...). As observed below, the spin-crossover particle switches from LS at $150 \mathrm{~K}$ to HS at $170 \mathrm{~K}$ with a related $2 \%$ volume dilatation. The structural relaxation of liquid 1-butanol occurs on a short timescale (typically nanoseconds) in the temperature range of the SC transitions, which is well above the glass transition. It implies that the matrix can adapt to the volume changes of the particles, leaving the characteristics of the spin transition (b) almost unchanged with respect to the case of free particles. This situation is obviously different for solid matrices that resist to deformation, suggesting that mechanical effects in the particle-medium interaction should be considered. On heating, the shift to higher temperature of the LS-to-HS transition (c $\uparrow$ ) illustrates the necessary rearrangement of the environment of the embedded particle in order to compensate its volume expansion and conversely, the positive stress applied to the particle. The relative stabilization of the LS SC species under the effect of an applied pressure 39,40 and the upshift of the transition temperature are well documented features but only a few examples can be found for which $\mathrm{T}_{1 / 2}$ increases when LS nanoparticles coated with a silica shell feel a positive pressure. Other possible explanations were pinpointed in these analyses as a pre-existing cooperative hysteresis $\underline{15,13}$ or the matrix desolvation. $\underline{18, \underline{41}}$ On cooling, the shift to lower temperature of the HS-to-LS transition (c $\downarrow$ ) could result from the combination of different mechanisms including the local rearrangement of the matrix and the breaking of matrix-particle interactions. $\underline{22}$ For subsequent cycles (d), the stabilization of both transitions to smaller values of the temperature shift indicates that the first HS-to-LS transition $(\mathbf{c} \downarrow)$ induces irreversible transformations of the solid matrix (e.g. plastic deformation and interaction cut-off), which are relaxed in the liquid phase. A similar shift was reported for spin-crossover particles embedded in glassy glycerol. $\underline{23}$ In the latter case, it was even shown that the stress induced by the volume expansion of the particles at HS-to-LS transition could produce cracks in the matrix, as revealed by the presence of spikes in the DSC measurements. No such observation of cracks was made in the present case, which suggests that the matrix local deformation does not propagate. This difference could indicate a weaker matrix-particle interaction (as confirmed below) or could be due to the less brittle character of 1-butanol crystal with respect to glycerol. The maximum peak intensities that systematically weaken after the crystallization of $\mathrm{BuOH}$ recover their initial value determined in the liquid. The hypotheses explaining this reversible weakening are the smoothening of the SC process (distribution of environments in the crystalline matrix) or the thermal changes (see below). Finally, we address how the entanglement between the phase transitions of both the matrix and the embedded SC particles determines the specific properties of the composite system along different thermal paths. Bearing in mind that thermal paths result from a succession of different types of SC transitions that were listed in Tab. 2, the properties of the composite can be rationalized (and directed on purpose) as shown in Fig 3. The composite system is defined by two parameters, corresponding to the state of the SC-particles (being either LS or HS) and that of the matrix, which assumes three values (liquid, unrelaxed crystal, and relaxed crystal). These two parameters stand for the two axes in Fig. 3. The transformations of 
the composite system between the six different states can be induced by a spin transition of the particles (thin arrows) or a transformation of the matrix (thick arrows). The free SC particles can be reversibly transformed from the LS to the HS states by thermal cycling through a succession of transitions of type $(\mathbf{a} \downarrow)$ and $(\mathbf{a} \uparrow)$.

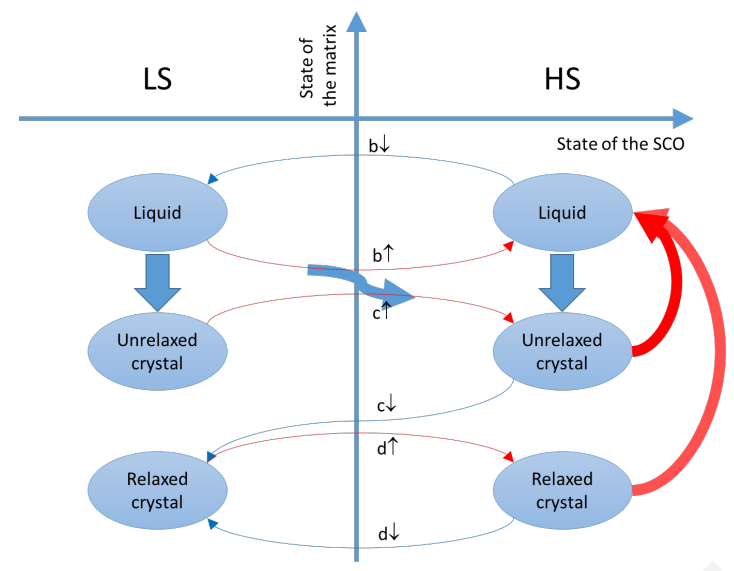

Figure 3. Schematics of the different thermodynamical paths going across the multiple phase transitions of the SC particles / 1-butanol matrix composite system. The crystalline phases of 1butanol are denoted as relaxed or unrelaxed crystal depending on the particle-matrix interaction.

However, two phenomena break this reversibility in the case of the SC-particles / 1-butanol composite system. First the metastable character of the supercooled liquid 1-butanol implies that the crystallization of the matrix, if occurs, is an irreversible event (thick blue arrows pointing downward in Fig. 3). The second phenomenon is the irreversible variation of the interaction between the SC-particles and the crystalline matrix, which occurs during the first spin transition. This is illustrated in Fig. 3 by the thin arrow $(\mathbf{c} \downarrow)$ that points downward to the ultimate situation where reproducible transformations of type $(\mathbf{d} \downarrow)$ and $(\mathbf{d} \uparrow)$ are obtained by further cycling in the relaxed crystalline matrix. The full recovery of the system following the occurrence of these two irreversible phenomena can be only obtained by heating above $\mathrm{T}_{\mathrm{m}}$ up to its initial stage (thick red arrows pointing upward in Fig. 3).

As a concluding remark of this part, it should be pointed out that the system can be driven on purpose along the different thermodynamic paths shown in Fig. 3 by a careful choice of a set of control parameters (temperature, rate etc.). A direct illustration came from the specifically designed thermal treatments, which we applied to study the transitions of SC particles within different types of matrices discussed previously. Cycling between $\mathrm{T}_{\max }=200 \mathrm{~K}$ and $\mathrm{T}_{\min }=150 \mathrm{~K}$ (scanning rate $1 \mathrm{~K} \mathrm{~min}^{-1}$ ) produced both spin transitions in a liquid matrix (b $\left.\downarrow\right)$ and $(\mathbf{b} \uparrow)$ as shown in Fig. S6. However, the replication of multiple cycles in the liquid phase seemed restricted by partial crystallization, which slowly occurred either on heating above $\mathrm{T} \uparrow$ - an issue that could be circumvented by selecting a lower value of $\mathrm{T}_{\max }$ (e.g. $165 \mathrm{~K}$ ) - or during the LS-toHS transition itself, as suggested in Fig. S6, by a broad weak exothermic peak. This concomitant crystallization and spin-transition is shown in Fig. 3 as a curved blue arrow forming a crossover from a transition of type (b $\uparrow$ ) to type (c $\uparrow$ ). All the different types of transition can be induced with a deeper cooldown, as shown in Fig. 4 where successive thermal cycles were performed between $\mathrm{T}_{\max }=200$ (or 180) and $\mathrm{T}_{\min }=100 \mathrm{~K}$. 


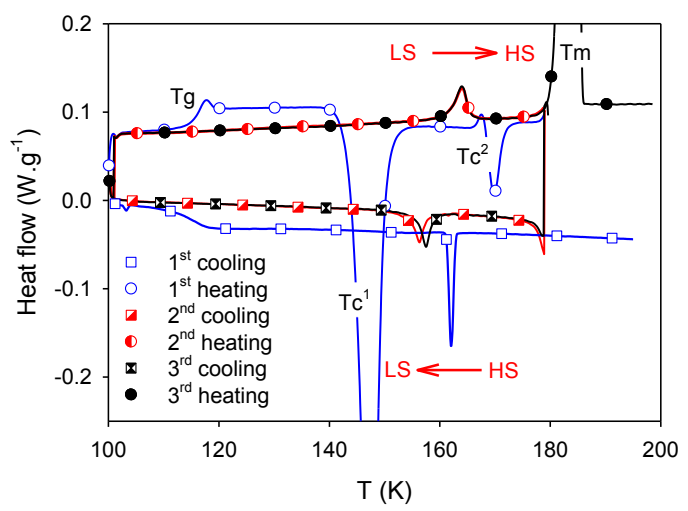

Figure 4. Total heat flow of the m-DSC thermogram $\left(1 \mathrm{Kmin}^{-1}\right)$ of bulk particles embedded in 1butanol cycled in the temperature range 100-200 K. The six consecutive cooling/heating branches illustrate the transitions sequence $(\mathbf{b} \downarrow),(\mathbf{c} \uparrow),(\mathbf{c} \downarrow),(\mathbf{d} \uparrow),(\mathbf{d} \downarrow),(\mathbf{d} \uparrow)$ presented in Fig. 3.

The nature of the matrix (liquid or crystal) is attested by the presence or the absence of a glass transition $\left(\mathrm{T}_{\mathrm{g}}=115.5 \mathrm{~K}\right)$, along with peaks indicating crystallization on first heating $\left(\mathrm{T}_{\mathrm{c}}=147.5\right.$ $\mathrm{K})$ and melting during the last heating $\left(\mathrm{T}_{\mathrm{m}}=183.5 \mathrm{~K}\right)$. It shows that cycling between 180 and 100 $K$ induces the following sequence of transitions $(\mathbf{b} \downarrow),(\mathbf{c} \uparrow),(\mathbf{c} \downarrow),(\mathbf{d} \uparrow),(\mathbf{d} \downarrow),(\mathbf{d} \uparrow) \ldots$ until the initial liquid state is recovered by the final heating up to $200 \mathrm{~K}$.

As the encapsulation in $\mathrm{BuOH}$ influences the transition of bulky objects, we pursued the experiments with needle-shaped microcrystals ( $8 \mu \mathrm{m}$ long).

In-BuOH Microcrystals. The dispersion of particles in the liquid keeps unchanged the $\mathrm{T}_{1 / 2}$ value and shifts the position of maxima by 1-2 K (Fig. S7, Tab. S1). In comparison to the pure sample, the shape of the transition peaks is less asymmetric but broadened. Because of the scanning rate of $10 \mathrm{Kmin}^{-1}$, the formation of the glacial phase of $\mathrm{BuOH}$ is prevented and here we can observe how the crystallization of triclinic phase influences the process of spin transition. The LS-to-HS signal is detectable but essentially convoluted with that of $\mathrm{BuOH}$. Further cooling or heating cycles result in a net decrease of intensity (by a factor $\sim 6$ ), the broadening and the shift (a several K downshift of the HS-to-LS branch) of SC peaks. So, upon the thermal cycling in 1butanol, similar evolutions characterize the bulk and microcrystals samples considered hereafter as bulk-like ones.

As pointed above, the dampening of the signal intensities can be due to changes in the thermal contacts and the heat dissipation. For addressing this issue, we use magnetic measurements that, contrarily to DSC, are sensitive to the fraction of HS species and allow a quantitative analysis of the spin crossover.

\section{B. Thermal Spin-Transition and Bistability of Composite Systems: Magnetic Study}

The Fig. S8 shows the cooperative first-order spin transition of the pure $\mathrm{Fe}^{\mathrm{III}}\left(3-\mathrm{OMeSalEen}_{2} \mathrm{PF}_{6}\right.$ material $\left(\mathrm{T}_{1 / 2}=163 \mathrm{~K}, \Delta \mathrm{T}=\mathrm{T} \uparrow-\mathrm{T} \downarrow=2 \mathrm{~K}, 1 \mathrm{Kmin}^{-1}\right)$. 26 The effect of a 1-butanol environment was studied by reproducing the experimental conditions used in calorimetry, i.e. the sequence of thermal cycles (at $1 \mathrm{Kmin}^{-1}$ ) and the samples preparation (34wt-\%). Accordingly we can discuss the observations in relation with the schematics and the labels of Fig. 3. 


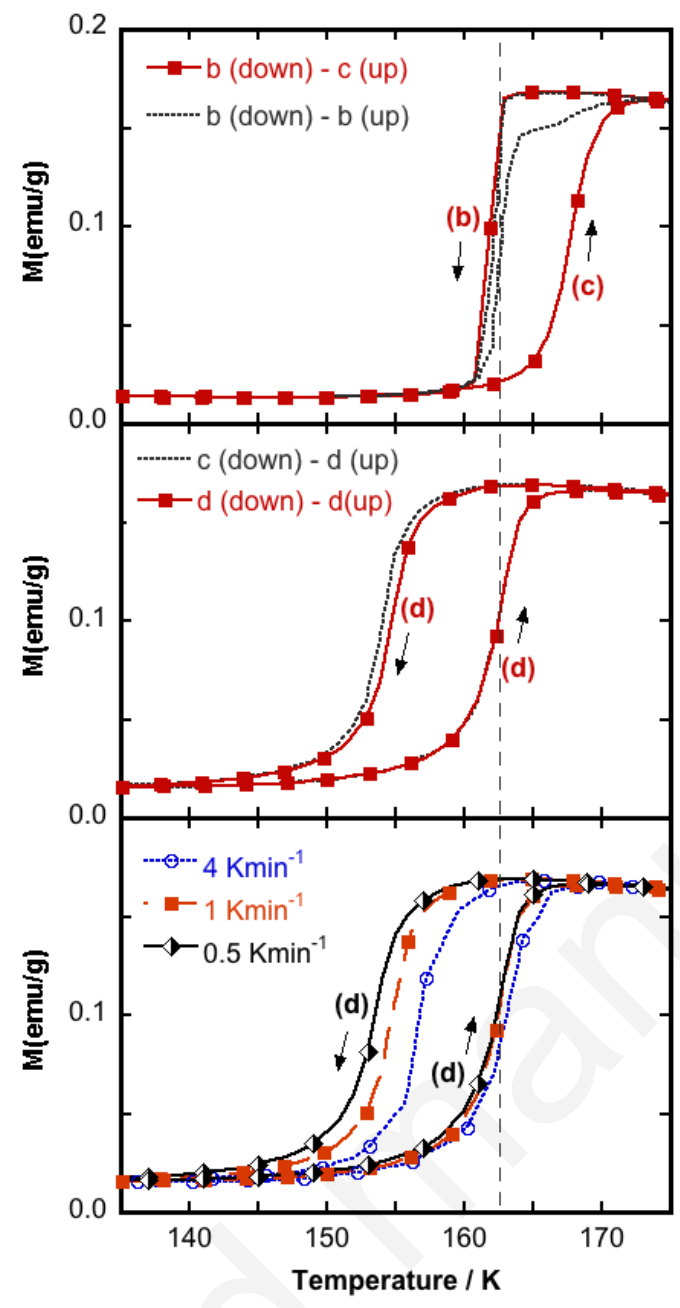

(i)

(ii)

(iii)

Figure 5. Magnetization vs temperature plots $\left(1 \mathrm{Kmin}^{-1}\right)$ of bulk particles embedded in 1butanol. After the thermalization $(200 \mathrm{~K}, 30 \mathrm{~min})$ : (i) the $180-150 \mathrm{~K}$ cycle $(---, \mathbf{b} \downarrow$ and $\mathbf{b} \uparrow$, liquid) and the first $180-100 \mathrm{~K}$ cycle $(\mathbf{\square},-, \mathbf{b} \downarrow$ and $\mathbf{c} \uparrow$, crystallization in progress, glacial phase) ; (ii) the second ( $\mathbf{\square}, \mathbf{c} \downarrow$ and $\mathbf{d} \uparrow$, (un)relaxed crystal, triclinic phase) and third 180$100 \mathrm{~K}$ cycle $(\boldsymbol{\square},-, \mathbf{d} \downarrow$ and $\mathbf{d} \uparrow$, relaxed crystal, triclinic phase). In (iii), scanning ratedependent hysteresis observed after the butanol crystallization (d, relaxed crystal). The broken line corresponds to $\mathrm{T}_{1 / 2}=162.5 \mathrm{~K}$ value for in-liquid butanol particles.

In-BuOH Bulk Material. In addition to the remarkable sensitivity of the magnetic behavior to the matrix transformation, Figure 5 (Tab. 1) indicates that the percentage of the SC metal ions is unchanged whatever the phase of 1-butanol. The matter dispersed in liquid butanol $\left(\mathrm{T}_{\min }=150\right.$ $\mathrm{K}$ ) retains the same SC properties as the pure one (Fig. 5-i).

The anomaly on heating (b $\uparrow$ ) results from the partial crystallization of matrix as demonstrated by changing the kinetic at $0.5 \mathrm{Kmin}^{-1}$ (Fig. S9). Consistently, the solidification of butanol $\left(\mathrm{T}_{\min }<\right.$ $150 \mathrm{~K}$, glacial phase) gives rise to the opening of a hysteresis loop primarily due to the abrupt LS-to-HS transition (c $\uparrow$ ) that is positively shifted $(+4 \mathrm{~K})$ with respect to free particles. In Fig. 5-ii (next 180-100 K cycle), the previous behavior disappears to the benefit of a new cooperative one $\left(\mathrm{T}_{1 / 2} \sim 157 \mathrm{~K}, \Delta \mathrm{T}=8-10 \mathrm{~K}, \mathbf{c} \downarrow\right.$ and $\mathbf{d} \uparrow$ ). This hysteretic regime is reproduced twice (Fig. 5-ii) with minor changes in the cooling branch, which correspond to the particles experiencing 
unrelaxed (c) and then relaxed (d) interactions with the crystalline matrix (triclinic phase). It is noteworthy that the hysteresis loop (d) is detected whatever the scanning rate from 4 to 0.5 $\mathrm{Kmin}^{-1}$ (Fig. 5 -iii) and this feature does not require the composite transformation via the $\mathbf{c} \uparrow$ path (LS-to-HS transition under stress). Interestingly, the slower scanning rate allows maximizing the negative shift and the hysteresis width (from ca. 6 to $9 \mathrm{~K}$ ). This evolution is opposite to what would result from a dynamical thermalization upon the spin-state switching. Since, the 1butanol is thermodynamically stable once transformed in the triclinic phase, as confirmed by DSC, the enhancement of cooperativity can suggest slow changes in the microstructure, the corresponding stress and matrix stiffening, factors that have been previously pointed. 27 It could also be accounted for by an imperfect crystallization of 1-butanol, especially in the vicinity of the interface with the SC particle where a few layers of butanol could be in the form of supercooled liquid according to its low-temperature glass transition. In Fig. S10b, the freezing of butanol below its glass transition leads to a spin transition that duplicates all the characteristics previously observed upon the crystallizations of butanol (paths $\mathbf{c} \uparrow, \mathbf{c} \downarrow$ and $\mathbf{d}$ ). Accordingly it results in a $12 \mathrm{~K}$-wide loop that narrows $(7 \mathrm{~K})$ in the second cycle but without noticeable change of temperature $\left(\mathrm{T}_{1 / 2}=\right.$ ca. $160 \mathrm{~K}<\mathrm{T}_{1 / 2}$ liq $)$.

Nanocrystals. Compared to the bulk, the SC behavior of pure $460 \mathrm{~nm}$-long platelets (Figs. 6 and S11) is consistent with the effect of size reduction (decrease of cooperativity and transition temperature). 27 The embedding in liquid butanol (b) does not change the transition temperature $\left(\mathrm{T}_{1 / 2} \sim 158 \mathrm{~K}\right.$ ), but slightly improves the cooperativity (inset in Fig. 6). The liquid-to-crystal transition of butanol $\left(\mathrm{at} \mathrm{T}_{\mathrm{c}}{ }^{1}\right.$ ) shifts the LS-to-HS transition (c $\uparrow$ ) in a similar manner to the bulk one (Fig. 6, S11b-c) if the heating rate is slowered $\left(0.5 \mathrm{Kmin}^{-1}\right)$ because of the decrease of the $\mathrm{T}_{1 / 2}$ value and the rate of butanol crystallization. In the next cycle (after the sample heating at $170 \mathrm{~K}$ ), the $\mathrm{M}$ vs. $\mathrm{T}$ plot shows distinctive features assignable to the size distribution of the particles. The transition of the smaller-size particles is reversible, broadened and strongly shifted $\left(\mathrm{T}_{1 / 2} \sim 147 \mathrm{~K}\right)$ while that of larger-size particles is associated to a reproducible hysteresis ( $\mathrm{T}_{1 / 2} \sim 154 \mathrm{~K}, \mathbf{c} \downarrow, \mathbf{d} \uparrow$ branches) whose characteristics (width, spreading) depend on the thermal preparation as previously described.

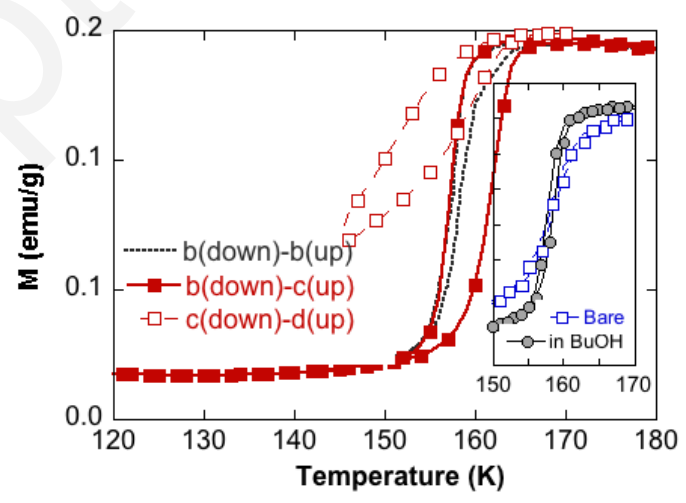

Figure 6. Magnetization vs Temperature plots of the nanoparticles embedded in butanol $(0.5$ $\mathrm{Kmin}^{-1}$ ) recorded after a thermalization at $200 \mathrm{~K}$ (30 min): one 180-150 K cycle (---, b), the 180 $100 \mathrm{~K}$ cycle ( $\mathbf{\square}, \mathbf{b} \downarrow$ and $\mathbf{c} \uparrow$ ) then, after a thermalization at $145 \mathrm{~K}(30 \mathrm{~min})$, the $170-100 \mathrm{~K}$ cycle ( $\mathbf{\square}, \mathbf{c} \downarrow$ and $\mathbf{d} \uparrow$ ). In the inset: the $180-150 \mathrm{~K}$ cycle $\left(1 \mathrm{~K} \mathrm{~min}^{-1}\right)$ recorded with bare particles $(\square)$ embedded in liquid butanol (----, b). 
The parallel between the behavior of the $460 \mathrm{~nm}$-long particles and the bulk is instructive. In both cases, the matrix stiffening at $\mathrm{T}_{\mathrm{c}}{ }^{1}$ taking place from the liquid state similarly shifts the LSto-HS transition towards higher temperature values. This point confirms that the size-reduction is not large enough to alter the mechanical properties of the particles as it was carefully established in the case of ultra-small SC nanoparticles. ${ }^{42}$ It comes from the study of this SC material under an applied external pressure that the transition temperature linearly increases by 16.4(1.0) $\left.\mathrm{K} \mathrm{kbar}^{-1}\right) . \underline{43}$ By assuming a limited deviation of hydrostaticity in the composite, the stress exerted by the crystalline matrix on the bulk or nanoparticles can be estimated at ca. 240 bar ( $\mathbf{c} \uparrow$ branch, $\Delta \mathrm{T}_{1 / 2}=+4 \mathrm{~K}$ ). Moreover, the size - dependent features suggest that the effect of elastic forces, connectivity and variable negative pressure prevail when the size reduction is large enough.

To sum up this part, the study of bulk-type samples shows that all the magnetic features are remarkably consistent with those determined by calorimetry (see Tab. 1). Slight variations of the $\mathrm{T}_{1 / 2}$ values occur from the intrinsic difference between the measurement of magnetization and that of the rate of heat flux. The preservation of the SC completeness through the whole sequence corroborates our analysis of the enthalpy variations upon the matrix solidification (c, $\mathbf{d}$ cycles in Tab. 1-2). The spreading of the final branches of hysteresis $(\mathbf{d} \downarrow, \mathbf{d} \uparrow)$ is indicative of broadened distributions of $\mathrm{T}_{1 / 2}$ values that derive from the particles - environment characteristics. The hysteresis loop widens for particles embedded in the stiffer medium crystalline (d) vs. liquid (b)- and its observation depends on the particle size. Accordingly, these results have to be discussed in terms of elastic interactions or cooperativity on the basis of a proper analysis.

\section{Cooperativity and Hysteretic Behavior of the Composite: the First-Order Reversal Curves Study.}

Since the information provided by the major hysteresis loops is inherently somehow limited, for a deeper understanding of the effect of the embedding matrix on the SC systems we have used the first-order reversal curves (FORC) method, which is known as a powerful characterization tool for the hysteretic behavior in materials. FORC method consists in recording a series of minor hysteresis loops, for which the sweep of the input parameter (here the temperature) is reversed just once from the major hysteresis branches. Then, the FORC distribution is defined as the second-order mixed derivative of the high-spin fraction parameter:

$$
\rho\left(T_{A}, T_{B}\right)= \pm \frac{\partial^{2} n_{H S}}{\partial T_{A} \partial T_{B}}
$$

where the negative sign is for the heating mode (FORCs starting from the decreasing temperature branch), and the positive sign is for the cooling mode (FORCs starting from the increasing temperature branch). It was shown that the FORC distribution is similar to the statistical distribution of the switching temperatures and coercivities of individual grains, the latter being spin-like domains (bulk) or merely single microcrystals embedded in matrices.

In Fig. 7a, we present FORCs in the heating mode (FORCs in the cooling mode can be found in Fig. S12), based on magnetic measurements (scanning rate $=0.2 \mathrm{Kmin}^{-1}$ ) for bulk and $8 \mu \mathrm{m}$-long particles in 1-butanol, that in contrast to the previous experiments, were several times thermally cycled for (i) averaging the SC characteristics by the self-grinding effect $\underline{44}$ and (ii) preparing the 
composite in the crystal relaxed state (d). The behavior of both samples qualitatively reproduces the DSC observations in Fig. S7 (or Fig. 5iii) if we take into consideration the effect of selfgrinding and for the microparticles, that of size reduction. $\underline{32}$

The FORCs analysis is relevant for extracting original and qualitative information on the particle-matrix systems. We notice that FORCs have a close-to-zero slope at the reversal temperature, which is expected in case of free bulk particles $\underline{33}$ but very different compared to the microparticles of $\mathrm{Fe}(\text { phen })_{2}(\mathrm{NCS})_{2}$ embedded in glycerol eicosane, nujol or paratone. 45 This intriguing behavior has been related to the temperature- and time-dependent properties (elasticity and plasticity) of the particles-matrix composite. Thus, in the Fe(phen) $)_{2}(\mathrm{NCS})_{2}$ case,, 22 non-zero slope of FORCs is due to the variable local pressure around every HS particle, determined by the stiffening of the glassy (or semicrystalline) matrix around HS particles, the volume change of spin crossover particles and the resulting elastic forces (physisorption). As carefully established above, the present hysteresis results from the influence of the 1-butanol crystallization and relaxation processes on the HS-to-LS and the LS-to-HS transitions (d). The full set of FORCs confirms that (i) the cooperativity is strengthened upon the crystallization process; (ii) only a limited number of particles-matrix interactions may be switched on and cut off in the case of crystalline BuOH. In Fig. 7b, we present FORC diagrams for bulk particles of [Fe'II(3-OMeSalEen) $\left.{ }_{2}\right] \mathrm{PF}_{6}$ (left, heating mode) and microparticles (right, heating and cooling modes) embedded in $\mathrm{BuOH}$. In both cases we notice the absence of the reversible part, a feature that again suggests a minor role of elastic interactions. Moreover, the FORC diagrams of microparticles recorded in the cooling and heating modes exhibit a mirror symmetry with respect to the $\operatorname{Tr}=\mathrm{T}$ axis, which implies that the distribution of the switching temperatures is not process-dependent, i.e. does not change for heating and cooling processes.

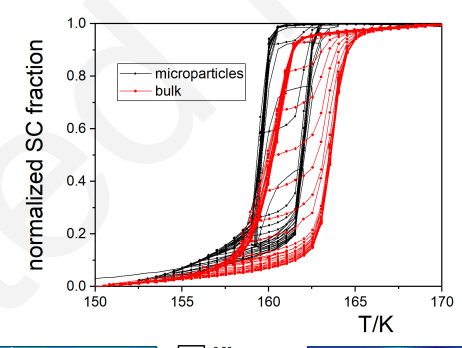

(a)
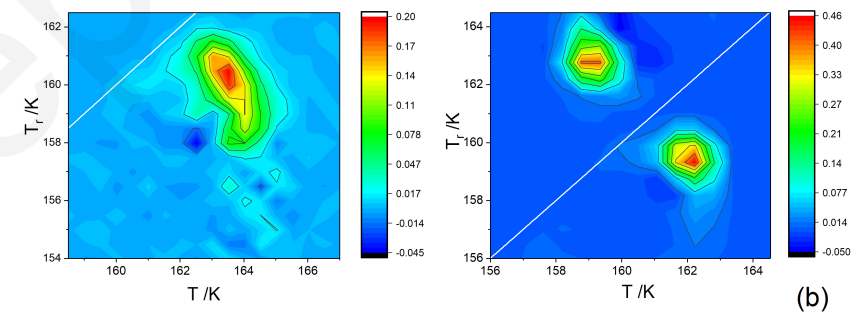

Figure 7. (a) Superposition of the First-order reversal curves in the heating mode for in-BuOH embedded [FeIII(3-OMeSalEen) ${ }_{2}$ ] $\mathrm{PF}_{6}$ bulk (red) and $8 \mu$ m-long (black) particles. The samples were previously cycled and brought out in the stable hysteretic regime (d, sweeping rate $=0.2$ $\mathrm{Kmin}^{-1}$ ). The FORC plots recorded in the two branches of the major hysteresis show a zero slope at any reversal temperature; (b) Corresponding FORC distributions in the heating mode for bulk (left) and in both modes for $8 \mu \mathrm{m}$-long particles (right).

This is similar to non-interacting spin-like domains observed for the spin-crossover compound $\left[\mathrm{Fe}(\mathrm{btr})_{2}(\mathrm{NCS})_{2}\right] \cdot \mathrm{H}_{2} \mathrm{O}$, prepared as bare powder. Here, every microparticle embedded in $\mathrm{BuOH}$ 
can be seen as a single domain, with a statistically stable distribution of interactions (constant local pressure) due to the matrix despite of the change in volume of spin-crossover particle as explained above.

The $\mathrm{BuOH}$ based matrices induce a completely different behavior to the microparticles compared to the rest of the environments previously studied (e.g. glycerol, nujol, etc ...), looking rather closer to the bulk. The transition of the microparticles mediated by the $\mathrm{BuOH}$ matrix, no matter which process (heating or cooling) we are looking at, is sharper compared to the bulk as is revealed by the maximum value of the distribution. The microparticles diagrams are almost two folds higher than the bulk diagram. It follows that the environment provided by the $\mathrm{BuOH}$, accelerates the switching of the microparticles, thus having place in a smaller temperature interval compared to the bulk.

As a conclusive remark of this part, relatively bulky particles embedded in a stiff and thermodynamically stable matrix of crystalline butanol exhibit a thermal hysteresis arising from an enhancement of cooperativity. This cooperative mechanism prevails over the one involving the switching on-cutting off of elastic forces and favored by the reversible rearrangement of the particles environment (proximity of glass transition) upon the SC process. Simple thermodynamical considerations can justify this enhancement of cooperativity by a relative decrease of the environmental pressure (pressure deficit $\underline{46}$ due to the matrix solidification), all things equal otherwise (including cooperativity). However this statement neglects the additional contributions due to the composite nature of the material, which as shown above, involve thermodynamic, kinetic and mechanical (interfacial, texture, stiffness) properties.

Since the cooperativity is related to the structural and mechanical properties of the solid, it is interesting to study how the structural parameters of a single-crystal of [Fe"II (3$\mathrm{OMeSalEen}_{2} \mathrm{PF}_{6}$ is sensitive to a matrix, especially when the solidification takes place around a LS or HS lattice.

\section{Influence of the Coating on the Single-Crystal Phase Transition: the Structural Study}

The collection of unit-cell parameters (triclinic P-1 space group) as a function of temperature was first performed with a single-crystal without any external coating. Unfortunately, the crystals were damaged as quite often observed with very cooperative first-order spin transition materials, $\underline{47}$ so we focused our study on two single-crystals that were wrapped with 1-butanol and Paratone, a cryoprotectant. According to the temperature ramp, the butanol is a liquid film (b $\downarrow$ ) then it crystallizes at $\mathrm{T}_{\mathrm{c}}{ }^{1}(\mathbf{c} \uparrow)$ upon the single-crystal cooling and heating cycles respectively. The Paratone was selected because it solidifies in a temperature range where the crystal is HS (between 260 and 190 K, DSC data in Fig. S13).

The selection of volume and unit-cell parameters vs. temperature plots (Fig. 8 and Fig. S14 respectively) evidences the first-order nature of the cooperative phase transition of this material and also, changes between the two experiments (transition temperatures, amplitude and sign of the relative variations of parameters) which match with the two cases under study. For the crystal coated with butanol, the positions of cooling and heating branches of the hysteresis ( $\mathrm{T} \downarrow=$ $161.5 \mathrm{~K}, \mathrm{~T} \uparrow=167.5 \mathrm{~K}$ ) are comparable with those previously assigned to the $\mathbf{b} \downarrow$ and $\mathbf{c} \uparrow$ paths of the composite transformation. In contrast the Paratone coating is associated to the negative shift of the thermal hysteresis, as confirmed by the magnetic measurement of polycrystals (Fig. S15). 
The crystals dimensions being comparable and larger than those influencing the SC features,27,23 these modifications are thus related to the coatings deposited at the crystals surface. It can be added that if one excludes a weak fluctuation of the $c$ parameter, the whole dataset corresponding to the butanol coating is consistent with a publication of the group 26,22 in which unfortunately, the name of the cryoprotectant was omitted. The transition temperature associated to the Paratone coating $\left(\mathrm{T}_{1 / 2}=157 \mathrm{~K}\right)$ falls within the range found with a few pressure-transmitting matrices (Alcatel 100, Fluorinert FC77, Daphne 7373, $\mathrm{T}_{1 / 2}=157-160 \mathrm{~K}$ ) which also solidify when the particles of [Fe $\left.{ }^{\mathrm{III}}(3-\mathrm{OMeSalEen})_{2}\right] \mathrm{PF}_{6}$ are HS.43 The relationship between the stiffening of a Paratone environment in presence of HS species and the temperature shift of the hysteresis seems to be consistent with the behavior described above from the crystallization of 1-butanol (c $\downarrow$ path). Finally, we also remark some anomalies in Fig. 8 and S14, which appear by replacing 1-butanol by Paratone coating. In the temperature range of the spin transition, the $a$ parameter shows an opposite evolution while the $\alpha$ and $\gamma$ angles change relatively by $1 \%$ (Fig. 8).

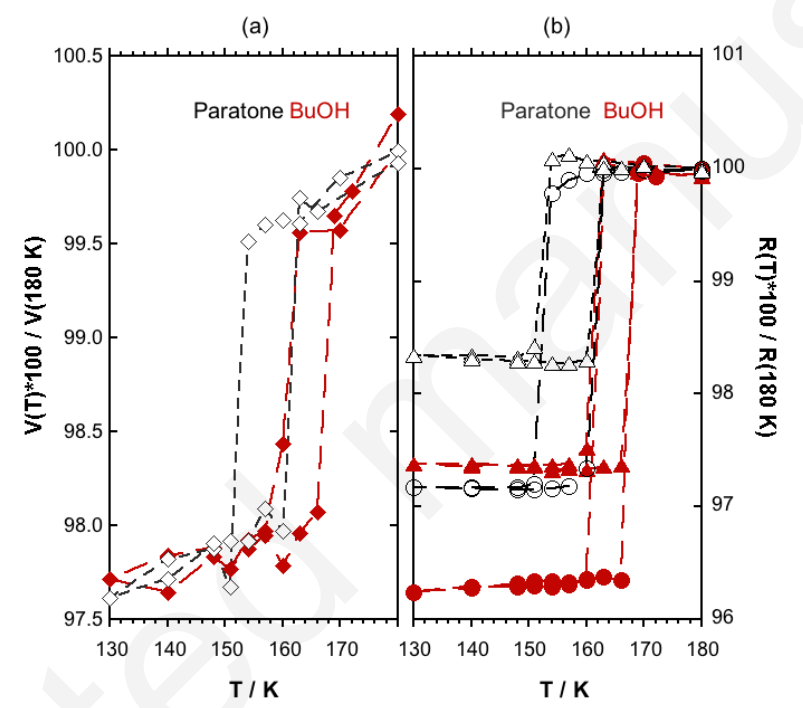

Figure 8. Relative evolution of the volume (in (a), $\mathrm{V}(\diamond)$ ) and the unit-cell angles (in (b), $\mathrm{R}=\alpha$ $(\bullet)$ and $\gamma(\boldsymbol{\Delta})$ ) recorded between 180 and $130 \mathrm{~K}$ for single crystals of [Fe $\left.{ }^{\mathrm{III}}(3-\mathrm{OMeSalEen})_{2}\right] \mathrm{PF}_{6}$ coated with $\mathrm{BuOH}$ (full symbol in red) and Paratone (open symbol in black).

The relative unit-cell volume being preserved, these findings could characterize an extramechanical effect, presumably of shearing type, which would derive from the stiffening of coating. Therefore this study of single-crystals wrapped with a thin layer of coater brings out some evidences suggesting that the solidification or the crystallization of this layer interferes with the structural characteristics of a first-order spin transition material via mechanical effects at the crystal surface.

\section{Experimental}

Chemicals. The polycrystalline powder of Fe $\left.{ }^{\mathrm{III}}(3-\mathrm{OMeSalEen})_{2}\right] \mathrm{PF}_{6}$ was synthesized as described in ref25,48,49. Single-crystals were isolated by recrystallization in acetone. Micro-

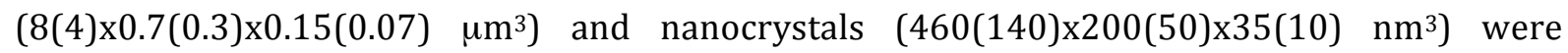
prepared by nanoprecipitation with an antisolvent.27 Synthetic details, TEM images (Fig. S1) and 
routine characterizations were shown in SI. Compare to the bulk, the surface/volume ratio of particles vary over ca. 3 orders of magnitude (from 0.2 to ca. $75 \mathrm{~mm}^{-1}$ ).

DSC measurements. They were performed with a Q-20a TA Instrument using aluminium hermetic pans and a scanning rate of 1 and $10 \mathrm{Kmin}^{-1}$. Indium value was used for the calibration of $\Delta \mathrm{H}$. All the experimental conditions used for collecting the DSC and magnetic data are detailed in SI.

Magnetic measurements. The magnetic susceptibility measurements were performed using a Quantum Design SQUID magnetometer (MPMS5S Model) calibrated against a standard palladium sample. The data were collected at a scanning rate of 4, 1 or $0.5 \mathrm{Kmin}^{-1}$ with an iterative regression algorithm and a magnetic field of 5000 0e. The samples (34wt-\% of SC polycrystalline powder dispersed in 1-butanol) were thermally cycled according to the conditions defined above for the calorimetric measurements.

FORC measurements. The curves were recorded using the "settle" function of a Quantum Design MPMS-XL SQUID device with an average temperature sweeping rate of $0.3 \mathrm{~K} / \mathrm{min}$, in order to stabilize the temperature and to minimize kinetic effects. Around $1 \mathrm{mg}$ of $2-3 \mathrm{wt}-\%$ dispersion of powder in $\mathrm{BuOH}$ was used for every measurement. We have checked that the FORCs of the bulk material recorded with the MPMS5S magnetometer at ICMMO, a larger amount of matter (32wt-\% of SC powder dispersed in 1-butanol) and a scanning rate of 0.2 $\mathrm{Kmin}^{-1}$ were essentially the same.

Single-crystal X-ray diffraction measurements. The temperature dependence of the unit cell parameters was determined with monochromatic Mo-K $\alpha$ radiation $(\lambda=0.71073 \AA)$ using a Bruker APEXII CCD diffractometer. The unit-cell parameters were recorded with single-crystals having similar dimensions $\left(0.18 \times 0.08 \times 0.01 \mathrm{~mm}^{3}\right.$, coating of $\mathrm{BuOH} ; 0.28 \times 0.12 \times 0.02 \mathrm{~mm}^{3}$, coating of Paratone) that were supported on capton and wrapped by a film of liquid. The data were continuously collected between 180,130 and then $180 \mathrm{~K}$, by slow successive temperature variations (i.e. a $3 \mathrm{~K}$ interval in the transition range) and thermalization stages within an accuracy of $\pm 1 \mathrm{~K}$. In order to obtain a good monitoring of the cell parameters, we studied the evolution of the orientation matrix coming from 60 degrees of oscillation of the crystal. Low temperature measurements were achieved with an Oxford Cryosystems $\mathrm{N}_{2}$ cryostream 700 which provide isothermal experiments at different temperatures. The program SAINT (V7.68A) as used to integrate the data.

\section{Conclusions}

The dispersion of the spin-transition material [Fe $\left.{ }^{\mathrm{III}}(3-\mathrm{OMeSalEen})_{2}\right] \mathrm{PF}_{6}$ in a liquid, glassy or crystalline environment of 1-butanol has allowed us to change the first-order phase transition through the matrix transformations and to promote an enhanced hysteretic behavior that persists as long as the matrix is kept in the thermodynamically stable crystal form. These findings were made possible by establishing the full diagram of the SC transition as a function of the matrix state and the thermal treatment. The importance of the mechanical stress due to the matrix stiffening on the low-spin and high-spin materials is evidenced by using two crystallization processes of 1-butanol, which specifically shift the transition temperature of LS (positive stress) and HS isomer (negative stress). The first SC alteration that follows the liquidto-crystal transition of butanol produces an abrupt and shifted transition of the LS domains that is similarly observed with single-crystal and powders of micro or nanocrystals as a consequence 
of a stress exerted by the matrix that is estimated to ca 240 bar. The FORC analysis of the persistent hysteresis observed in the last case, provides firm evidences of a cooperative mechanism on the contrary to our previous results, which characterized the interference between the matrix rearrangement upon the glass transition and the spin crossover (elastic forces and variable negative pressure). The prevalence of the former vs. the second mechanism is consistent with the fact that both the pressure deficit and the phase stability increase according to the sequence: amorphous, crystallization, i.e. with the long-range order. The reverse statement has been observed by reducing enough the particles size. The enhancement of the cooperativity is first justified by the matrix crystallization around the largest volume HS particles, which results in a negative mechanical stress. The observation of a time-dependent broadening of hysteresis while a macroscopic stabilization of the composite was reached (thermodynamically stable state of butanol, particles-matrix stress relaxation) suggests other possible contributions (presumably related to the matrix microstructure, stiffness or to the particle-matrix interface).

In a future direction, it would be interesting to further study the relationship between the cooperativity and the matrix crystallization with LS SC nanocrystals and to exploit these mechanical effects on a system exhibiting a transition closer to room temperature or on other bistable/functional composite materials. We feel that these exciting features are of interest not only for specialists working on the SC materials but also for chemists and physicists investigating at the mesoscale other volume-dependent phenomena.

\section{Conflicts of interest}

There are no conflicts to declare.

\section{Acknowledgements}

The work was supported by the CNRS and the French Ministry of Research. C. E. and R. T. thank the Romanian Ministry of Research and Innovation within Program 1, Development of the National RD System, and Subprogram 1.22, Institutional Performance, RDI excellence funding projects (Contract no. 34PFE/19.10.2018). D.M. acknowledges funding from Rennes Metropole and the European FEDER Fund. The collaboration between Romanian and French teams has been supported by PHC Brancusi. The present work has benefited from the core facilities of Imagerie-Gif, (http://www.i2bc.paris-saclay.fr) member of IBiSA (http://www.ibisa.net), supported by «France-BioImaging" (ANR-10-INSB-04-01), and the labex «Saclay Plant Science » (ANR-11-IDEX-0003-02).

\section{Notes and references}

1. C. Balazs, T. Emrick and T. P. Russell, Science, 2006, 314, 1107-1110.

2. Spin Crossover in Transition Metal Compounds I-III, Ed. P. Gütlich and H. A. Goodwin, Springer, Belin, 2004, vol. 233-235.

3. Spin-Crossover Materials: Properties and Applications, Ed. M.A. Halcrow, Wiley, Chichester, UK, 2013.

4. C.R. Chimie, 2018, 21, 1055-1300.

5. G. Molnár, S. Rat, L. Salmon, W. Nicolazzi and A. Bousseksou, Adv. Mater., 2018, 30, 1703862-n/a.

6. K. Senthil Kumar and M. Ruben, Coord. Chem. Rev., 2017, 346, 176-205. 
7. H. Peng, S. Tricard, G. Félix, G. Molnár, W. Nicolazzi, L. Salmon and A. Bousseksou, Angew. Chem. Int. Ed., 2014, 53, 10894-10898.

8. M. Giménez-Marqués, M. L. García-Sanz de Larrea and E. Coronado, J. Mater. Chem. C, 2015, 3, 7946-7953.

9. L. Salmon and L. Catala, C. R. Chim., 2018, 21, 1230-1269.

10. L. Stoleriu, P. Chakraborty, A. Hauser, A. Stancu and C. Enachescu, Phys. Rev. B, 2011, 84, 134102.

11. G. Félix, W. Nicolazzi, L. Salmon, G. Molnár, M. Perrier, G. Maurin, J. Larionova, J. Long, Y. Guari and A. Bousseksou, Phys. Rev. Lett., 2013, 110, 235701.

12. A. Slimani, K. Boukheddaden and K. Yamashita, Phys. Rev. B, 2014, 89, 214109.

13. C. Faulmann, J. Chahine, I. Malfant, D. de Caro, B. Cormary and L. Valade, Dalton Trans., 2011, 40, 2480-2485.

14. P. Durand, S. Pillet, E.-E. Bendeif, C. Carteret, M. Bouazaoui, H. El Hamzaoui, B. Capoen, L. Salmon, S. Hebert, J. Ghanbaja, L. Aranda and D. Schaniel, J. Mater. Chem. C, 2013, 1, 19331942.

15. J. M. Herrera, S. Titos-Padilla, S. J. A. Pope, I. Berlanga, F. Zamora, J. J. Delgado, K. V. Kamenev, X. Wang, A. Prescimone, E. K. Brechin and E. Colacio, J. Mater. Chem. C, 2015, 3, 7819-7829.

16. M. D. Manrique-Juárez, F. Mathieu, A. Laborde, S. Rat, V. Shalabaeva, P. Demont, 0. Thomas, L. Salmon, T. Leichle, L. Nicu, G. Molnár and A. Bousseksou, Adv. Funct. Mater., 2018, 28, 1801970.

17. Y. Raza, F. Volatron, S. Moldovan, O. Ersen, V. Huc, C. Martini, F. Brisset, A. Gloter, O. Stephan, A. Bousseksou, L. Catala and T. Mallah, Chem. Commun., 2011, 47, 11501-11503.

18. A. Tokarev, J. Long, Y. Guari, J. Larionova, F. Quignard, P. Agulhon, M. Robitzer, G. Molnar, L. Salmon and A. Bousseksou, N. J. Chem. 2013, 37, 3420-3432.

19. H. Voisin, C. Aimé, A. Vallée, A. Bleuzen, M. Schmutz, G. Mosser, T. Coradin and C. Roux, J. Mater. Chem. C, 2017, 5, 11542-11550.

20. O. Klimm, C. Göbel, S. Rosenfeldt, F. Puchtler, N. Miyajima, K. Marquardt, M. Drechsler, J. Breu, S. Förster and B. Weber, Nanoscale, 2016, 8, 19058-19065.

21. A. Tissot, C. Enachescu and M.-L. Boillot, J. Mater. Chem., 2012, 22, 20451-20457.

22. R. Tanasa, J. Laisney, A. Stancu, M.-L. Boillot and C. Enachescu, Appl. Phys. Lett., 2014, 104, 031909.

23. R. Tanasa, C. Enachescu, J. Laisney, D. Morineau, A. Stancu and M.-L. Boillot, J. Phys. Chem. C, 2019, 123, 10120-10129.

24. V. Davesne, M. Gruber, M. Studniarek, W. H. Doh, S. Zafeiratos, L. Joly, F. Sirotti, M. G. Silly, A. B. Gaspar, J. A. Real, G. Schmerber, M. Bowen, W. Weber, S. Boukari, V. D. Costa, J. Arabski, W. Wulfhekel and E. Beaurepaire, J. Chem. Phys., 2015, 142, 194702.

25. M. S. Haddad, M. W. Lynch, W. D. Federer and D. N. Hendrickson, Inorg. Chem., 1981, 20 , 123-131.

26. A. Tissot, R. Bertoni, E. Collet, L. Toupet and M.-L. Boillot, J. Mater. Chem., 2011, 21, 18347-18353.

27. A. Tissot, L. Rechignat, A. Bousseksou and M.-L. Boillot, J. Mater. Chem., 2012, 22, 34113419.

28. M. Reading, A. Luget and R. Wilson, Thermochim. Acta, 1994, 238, 295-307.

29. M. Sorai, in Spin Crossover in Transition Metal Compounds III, eds. P. Gütlich and H. A. Goodwin, Springer Berlin Heidelberg, Berlin, Heidelberg, 2004, DOI: 10.1007/b95426, pp. 153-170. 
30. W. Nicolazzi and A. Bousseksou, C. R. Chim., 2018, 21, 1060-1074.

31. O. Roubeau, M. Castro, R. Burriel, J. G. Haasnoot and J. Reedijk, J. Phys. Chem. B, 2011, 115, 3003-3012.

32. M. Sorai, R. Burriel, E. F. Westrum and D. N. Hendrickson, J. Phys. Chem. B, 2008, 112, 4344-4350.

33. C. Enachescu, R. Tanasa, A. Stancu, E. Codjovi, J. Linares and F. Varret, Physica B: Condens. Matter, 2004, 343, 15-19.

34. R. Tanasa, C. Enachescu, A. Stancu, J. Linares, E. Codjovi, F. Varret and J. Haasnoot, Phys. Rev. B, 2005, 71, 014431.

35. R.-M. Stan, R. Gaina, C. Enachescu, R. Tanasa, A. Stancu and R. Bronisz, J. Appl. Phys., 2015, 117, $17 \mathrm{~B} 323$.

36. P. Derollez, A. Hedoux, Y. Guinet, F. Danede and L. Paccou, Acta Crystallogr. Sect. B, 2013, 69, 195-202.

37. R. F. Tournier, Chem. Phys., 2019, 524, 40-54.

38. I. M. Shmyt'ko, R. J. Jiménez-Riobóo, M. Hassaine and M. A. Ramos, J. Phys. Condens. Matter, 2010, 22, 195102.

39. P. Gütlich, A. B. Gaspar, Y. Garcia and V. Ksenofontov, C. R. Chim., 2007, 10, 21-36.

40. C.-M. Jureschi, J. Linares, A. Boulmaali, P. R. Dahoo, A. Rotaru and Y. Garcia, Sensors, 2016, 16, 187.

41. T. Zhao, L. Cuignet, M. M. Dîrtu, M. Wolff, V. Spasojevic, I. Boldog, A. Rotaru, Y. Garcia and C. Janiak, J. Mater. Chem. C, 2015, 3, 7802-7812.

42. M. Mikolasek, G. Félix, H. Peng, S. Rat, F. Terki, A. I. Chumakov, L. Salmon, G. Molnár, W. Nicolazzi and A. Bousseksou, Phys. Rev. B, 2017, 96, 035426.

43. J. Laisney, H. J. Shepherd, L. Rechignat, G. Molnár, E. Rivière and M. L. Boillot, Phys. Chem. Chem. Phys., 2018, 20, 15951-15959.

44. C. Enachescu, R. Tanasa, A. Stancu, F. Varret, J. Linares and E. Codjovi, Phys. Rev. B, 2005, 72, 054413.

45. R. Tanasa, J. Laisney, A. Stancu, M.-L. Boillot and C. Enachescu, Appl. Phys. Lett., 2014, 104, -

46. K. Yokogawa, K. Murata, H. Yoshino and S. Aoyama, Jap. J. Appl. Phys., 2007, 46, 36363639.

47. O. Iasco, M. L. Boillot, A. Bellec, R. Guillot, E. Rivière, S. Mazerat, S. Nowak, D. Morineau, A. Brosseau, F. Miserque, V. Repain and T. Mallah, J. Mater. Chem. C, 2017, 5, 11067-11075.

48. M. S. Haddad, W. D. Federer, M. W. Lynch and D. N. Hendrickson, Inorg. Chem., 1981, 20, 131-139.

49. M. S. Haddad, W. D. Federer, M. W. Lynch and D. N. Hendrickson, J. Am. Chem. Soc., 1980, 102, 1468-1470. 